\title{
Trichomes and Cuticular Wax Morphology on Flag Leaves of Drought Sensitive and Drought Tolerant Wheat (Triticum aestivum L.) under Unfavourable Growth Conditions
}

\author{
Santosh Kumari ${ }^{1 *}$ and Vipin Kumar Verma ${ }^{2}$ \\ ${ }^{1}$ Division of Plant Physiology, Indian Agricultural Research Institute, New Delhi, India \\ ${ }^{2}$ Department of Pharmacology, All India Institute of Medical Sciences, New Delhi, India, \\ *Corresponding author
}

Keywords

drought, trichomes, terpene,

sesquiterpenes, wax morphology,

wheats,

Article Info

Accepted:

20 January 2020

Available Online:

10 February 2020

\section{A B S T R A C T}

The present study data indicate that wheat trichomes are glandular trichomes. The frequency and development of these trichomes was affected by irradiance. The density of trichomes was negatively correlated with number of phenolic compounds in wheats. Branched chain amino acid metabolism (Valine), long chain alkanes, alkenes and fatty acid metabolism are cultivar specific in wheat. Differential responses for phenol, lignans, terpene and sesquiterpenes are due to the difference in metabolic strategies of drought sensitive and drought tolerant cultivars under favourable and unfavourable growth conditions. Wax morphology was similar in both wheats. Water stress and unfavourable growth conditions induced wax formation in the contrasting wheats.

\section{Introduction}

Trichomes are outgrowths from epidermal cell and vary in size by number of cells and row of cells. Trichomes may be hair or glandular structures. Glandular trichomes may be stalk less or stalked. Various forms of trichomes have been associated with the odour and quality of terpene (Rodrigues et al., 2013, Moradkhani et al., 2010). The lemon balm essential oil is represented by $\beta$ caryophyllene and germacrene $D$. These chemicals have antispasmodic effect and insecticidal effect against mosquitoes (Pinhoda-Silvia et al., 2012, Kiran et al., 2007). The triterpene skeletons are precursors of sterols and bioactive compounds which help the plant to survive under biotic and abiotic stresses.

The sesquiterpenes and phenolic compounds are also components of wax and cuticle and play antioxidants activities (Corsi and Bottega, 1999). Polysaccharides have been detected in the pectin layer of trichomes in Mentha pelegium. The essential oil 
components associated with trichomes are widely used in cosmetics, health and food industry.

A plant without trichomes is said to be glabrous and with trichomes is pubescent. Trichomes play protective role in reducing radiation load and loss of water by evaporation from the leaf surface. It is the glandular trichomes which produce and accumulate essential oils/ metabolic products between the cell wall and cutin. Sucrose esters containing short branched and straight chain acyl acids in exudates of tobacco are products of branched chain amino acid catabolism (Kandra et al., 1990) to recover carbon as succinyl CoA, acetyl CoA and Acetoacetate. Key enzymes; limonene cyclase and limonene hydroxylase in the synthesis of carvone are reported to be localized in gland cells of spearmint (Gershenzon et al., 1987). Environmental factors can modulate the primary and secondary metabolism in wheat cultivars. Therefore, trichomes and cuticular wax morphology were analysed in relation to secondary metabolites in flag leaves of drought sensitive and drought tolerant wheat (Triticum aestivum L.) under unfavourable growth conditions.

\section{Materials and Methods}

Drought sensitive wheat cultivar, HD2428 and drought tolerant wheat cultivar- C306 were grown at different dates (November 15, 2017 and January 15, 2018) to expose them to normal and oxidative stress environment under late sown conditions. Plants were grown in green house in earthen pots (size $30 \times 30 \mathrm{~cm}$ ) filled with sandy loam soil and farmyard manure in 3:1 under natural environment. Each pot was fertilized corresponding to 120,90 and $60 \mathrm{~kg}$ ha- 1 of $\mathrm{N}$, $\mathrm{P}$ and $\mathrm{K}$, respectively. Plants were kept free from diseases.

Flag leaves at ear emergence stage were sampled and ground in liquid $\mathrm{N}_{2}$, homogenised in methanol, evaporated to dry powder and dissolved in methanol (HPLC grade) for GC-MS analysis [GCMS-QP2010 Plus]. Flag leaves were used for scanning electron microscopy (SEM) under microscope LEO 435 VP (Fei Electron optics).

\section{Results and Discussion}

The present study GC-MS data clearly exhibit the presence of branched chain amino acid Valine as main metabolite in drought tolerant wheat cultivar HD2428 under favourable growth conditions. Diethyl phthalate is dominant secondary metabolite in C306, drought tolerant cultivar of wheat under favourable growth conditions. Valine was detected in C306 under oxidative stress creating conditions of high radiation and temperature i.e. unfavourable growth conditions.

Therefore valine indicates that drought sensitive cultivar use senescence to mobilize carbon and nitrogen for emerging ear and flag leaf development. Therefore, aromatic amino acids are already present for the synthesis of aromatic constituents detected in various essential oils. C306 exhibit (1, 2-Benzene dicarboxylic Acid i.e. Diethyl ester of Phthalic acid) the use of pentose phosphate pathway for the synthesis of aromatic acids.

Alpha Cadinene and Carene in HD 2428; Cadinene and Geraniol were contrasting metabolites in C306 under favourable growth condition. Carene and Azulenol were detected in C306 under unfavourable growth conditions. Octacosanol was contrasting alcohol in C306 cultivar of wheat. BetaCaryophyllene was not present under unfavourable growth conditions in the contrasting wheats (Table1). Transcaryophyllene and alpha pinene are main 
components of essential oil secreted and stored in glandular globular trichomes of Varronia curassavica a medicinal plant. Number of trichomes was higher (Plate 1A.) and wax formation was low (Plate 1) in drought sensitive cultivar HD2428 in contrast of drought tolerant cultivar of wheat C306 under both conditions. Our data indicate that wheat trichomes are glandular trichomes.

The frequency and development of these trichomes can be affected by irradiance (Gomes et al., 2009) due to reduction in leaf size and plant biomass in both wheats. The composition of oil can undergo oxidation reactions (Lima et al., 2003) under high temperature and radiation environment. The density of trichomes was negatively correlated with number of phenolic compounds in wheats. . Wax morphology was similar in both wheats. Water stress and unfavourable growth conditions induced wax formation in the contrasting wheats (Plate2.). Plate3A, 3B for HD2428 and 3C, 3D for C306 demonstrate that hydrogen peroxide mediates the increase in trichomes number under stress conditions. Drought tolerant cultivar of wheat exhibited higher number of phenols as compared to drought sensitive cultivar of wheat (Table1). Phenols and lignans participate in ROS detoxification under stress conditions.

Our data suggest that branched chain amino acid metabolism, long chain alkanes, alkenes and fatty acid metabolism are cultivar specific in wheat. Differential responses for phenol, lignans, terpene and sesquiterpenes are due to the difference in metabolic strategies of drought sensitive and drought tolerant cultivars under favourable and unfavourable growth conditions.

Table.1 GC-MS profile of trichomes and wax related metabolites in flag leaves of drought sensitive and drought tolerant wheat (Triticum aestivum 1.) Under unfavourable growth conditions

\begin{tabular}{|c|c|}
\hline HD2428-November & HD2428 -January \\
\hline $\begin{array}{l}\text { Butane, 2,2-Dimethyl- } \\
\text { Hexane, 3,3-dimethyl- } \\
\text { Octane, 4- Methyl- } \\
\text { Nonane, 1-iodo- } \\
\text { Pentadecane } \\
\text { Isooctanol }\end{array}$ & $\begin{array}{l}\text { Butane, 2,2-Dimethyl- } \\
\text { 1,1-Dicyclopropyl-2-Methyl-1-Pentene } \\
\text { Hexane, 3,3-dimethyl- } \\
\text { Octane, 6 Ethyl- 2 Methyl- } \\
\text { Nonane, 4,5-Dimethyl- } \\
\text { 2-Bromononan } \\
\text { 2,4,6,8-Tetramethyl-1-undecene } \\
\text { 1-Tetradecene } \\
\text { Decane, 1,2-Epoxy- } \\
\text { 1-Propene, 3,3'-Oxybis- } \\
\text { Diethyl Glycol monomethyl ester }\end{array}$ \\
\hline $\begin{array}{l}\text { Cyclohexene, 1-methyl-4-(1-methylethenyl)-, (S)- } \\
\text { Mentha-1,8-diene or Limonene }\end{array}$ & $\begin{array}{l}\text { Cyclohexene, 1-methyl-4-(1-methylethenyl)-, (S)- } \\
\text { Limonene }\end{array}$ \\
\hline
\end{tabular}




\section{1,3,3-Trimethyl-2-Oxabicyclo[2.2.2]Octane} Eucalyptol/\$\$ 1, 8-Cineol

3-Cyclohexene-1-Methanethiol, .Alpha.,.Alpha.,4Trimethyl-, Terpinyl acetate Naphthalene, 1,2,4a,5,6,8a-Hexahydro-4,7-

Dimethyl-1-(1-Methylethyl- $\alpha$-Cadinene Bicyclo[7.2.0]Undec-4-Ene, 4,11,11-Trimethyl-8Methylene-, [1R-(1R*,4E,9S*)]- $\beta$-Caryophyllene

Trimethyl Bicyclo [4.1.0] Hept-2-En-7-yl)-, (1.Alpha. 6. Alpha., 7.Alpha.)- Carene

**Valine

*Benzoic acid, 4-ethoxy-, ethyl ester/ Ethyl paraethoxybenzoate

Stigmasta-5,22-Dien-3.Beta.-Ol, Acetate

\section{C306-November}

Butane, 2,2-Dimethyl

Hexane, 3-Methyl-

Hexane, 3,3-Dimethyl

Heptane, 3,3,5-Trimethyl-

Heptane, 2,4-Dimethyl

Heptane, 1-Iodo-

Nonane, 4,5-Dimethyl-

Nonane, 1-Iodo-

Undecane, 5-Methyl

9-Eicosene, (E)-

9-Tricosene, (E)-

Propanedioic Acid, [1-[1-(1-Methylethenyl)-1-

Propenyl]Pentyl]-, Dimethyl

2-Propyldecan-1-Ol

1-Heptanol, 2,4-Dimethyl-,
2-Oxabicyclo[2.2.2]Octane, 1,3,3-Trimethyl- $\$$ 1, 8Cineol

Methyl (3-Oxo-2-Pentylcyclopentyl) Acetate- Cineol Alpha- Terpinyl acetate
Ethyl para-ethoxybenzoate

Stigmasta-5,22-Dien-3.Beta.-Ol, Acetate

\section{C306-January}

1-Propanamine, 2-Methyl-N-(2-Methylpropylidene 1,4-Pentadiene, 2,3,3-Trimethyl-

Hexane, 2,3,4-Trimethyl-

Heptane, 2,4-Dimethyl

Octane

7-Oxanonadecane

Undecane, 4-Methyl

Undecane, 4,7-Dimethyl

2,4,6,8-Tetramethyl-1-Undecene

1-Dodecene

1-Tetradecene

*Hexadecane, 1,16-Dichloro-

*1-Heptadecene

$\mathrm{N}$-Octadecane

(Trans)-2-Nonadecene

N-Tridecan-1-Ol

*Tetradecanal \$ \$ Myristaldehyde

*Tetradecan-1-Ol \$\$ 1-Hydroxytetradecane

2-Isopropyl-5-Methyl-1-Heptanol

E-4-Ethyl-1-Hydroxy-3-Nonen-2-One

*N-Octacosanol \$ \$ Cluytyl Alcohol \$ Montanyl Alcohol

Cyclohexene, 1-methyl-4-(1-methylethenyl)-/ -

Mentha-1,8-diene or Limonene 


\begin{tabular}{|c|c|}
\hline $\begin{array}{l}\text { 1,3,3-Trimethyl-2-Oxabicyclo[2.2.2] Octane } \\
\text { Eucalyptol/\$ 1, 8-Cineol }\end{array}$ & Methyl (3-Oxo-2-Pentylcyclopentyl) Acetate- Cineol \\
\hline $\begin{array}{l}\text { Naphthalene, 1,2,4a,5,6,8a-Hexahydro-4,7- } \\
\text { Dimethyl-1-(1-Methylethyl- } \alpha \text {-Cadinene }\end{array}$ & \\
\hline $\begin{array}{l}\text { 6-Octen-1-Ol, 3,7-Dimethyl-, Propanoate- } \\
\text { Geraniol }\end{array}$ & (2,2,6-Trimethyl-Bicyclo[4.1.0]Hept-1-yl)- \\
\hline $\begin{array}{l}\text { Terpineol, Acetate \$\$ Terpinyl Acetate } \\
\text { Bicyclo[7.2.0]Undec-4-Ene, 4,11,11-Trimethyl-8- } \\
\text { Methylene-, [1R-(1R*,4E,9S*)]- \$ 2,6,10,10- }\end{array}$ & $\begin{array}{l}\text { 3a(1H)-Azulenol, 2,3,4,5,8,8a-Hexahydro-6,8a- } \\
\text { Dimethyl-3-(1-Methylethy)-, [3R- } \\
\text { (3.alpha.,3a.alpha.,8a.alpha.)]-or(+)-Carotol }\end{array}$ \\
\hline $\begin{array}{l}\text { **Diethyl Phthalate } \\
\text { *Benzoic Acid, 4-Ethoxy-, Ethyl Ester }\end{array}$ & $\begin{array}{l}\text { 1,2-Benzenedicarboxylic Acid, Diethyl Ester } \$ \$ \\
\text { Phthalic Acid } \\
\text { *Benzoic Acid, 4-Ethoxy-, Ethyl Ester } \\
\text { Valine }\end{array}$ \\
\hline $\begin{array}{l}\text { *Phenol, 3,5-Bis(1,1-Dimethylethyl } \\
\text { 7,9-Di-Tert-Butyl-1-Oxaspiro(4,5)Deca-6,9- } \\
\text { Diene-2,8-Dione } \\
\text { Octanal, 2-(Phenylmethylene)- } \$ \$ 2 \text { - } \\
\text { Benzylideneoctanal }\end{array}$ & $\begin{array}{l}\text { *Phenol, 3,5-Bis(1,1-Dimethylethyl } \\
\text { 7,9-Di-Tert-Butyl-1-Oxaspiro(4,5)Deca-6,9-Diene- } \\
\text { 2,8-Dione } \\
\text { 2,6-Di(T-Butyl)-4-Hydroperoxy-4-Methylcyclohexa- } \\
\text { 2,5-Dien-1-One }\end{array}$ \\
\hline 2-Octyldodecan-1-Ol & 1-Octadecanol \\
\hline Stigmasta-5,22-Dien-3.Beta.-Ol, Acetate & Stigmasta-5,22-Dien-3.Beta.-Ol, Acetate \\
\hline
\end{tabular}
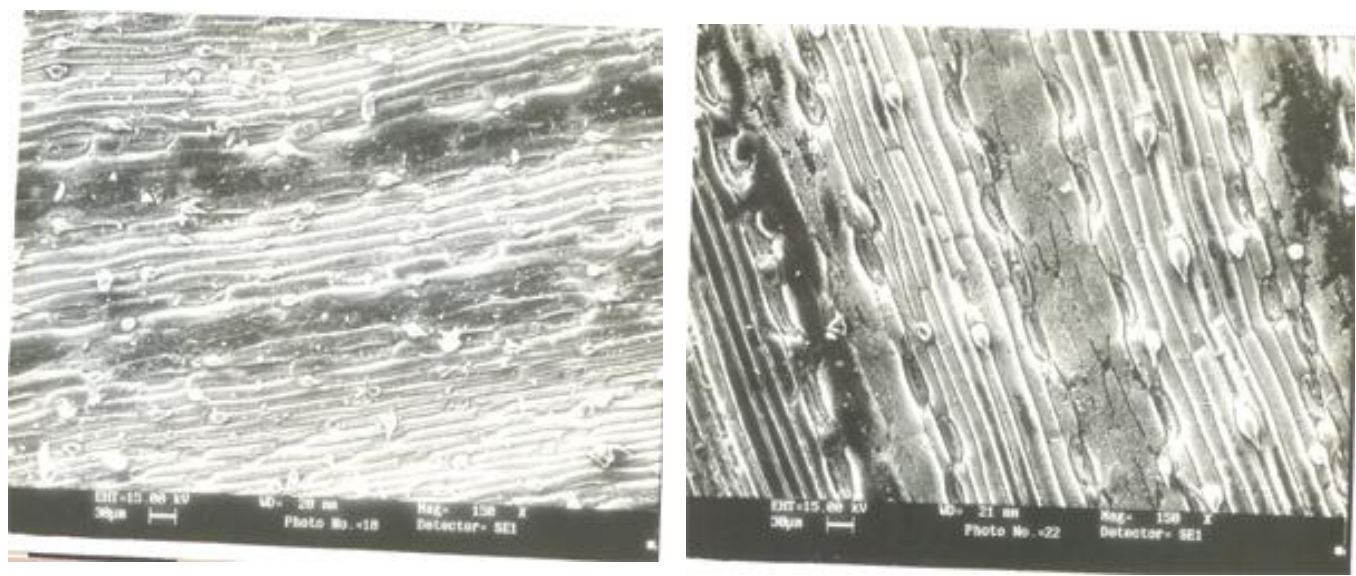

Plate.1A Trichomes and stomata on epidermal cells of drought sensitive (HD2428) and drought tolerant (C306) cultivar of wheat under unfavorable growth conditions (January sown) under low magnification to cover more leaf area in SEM 

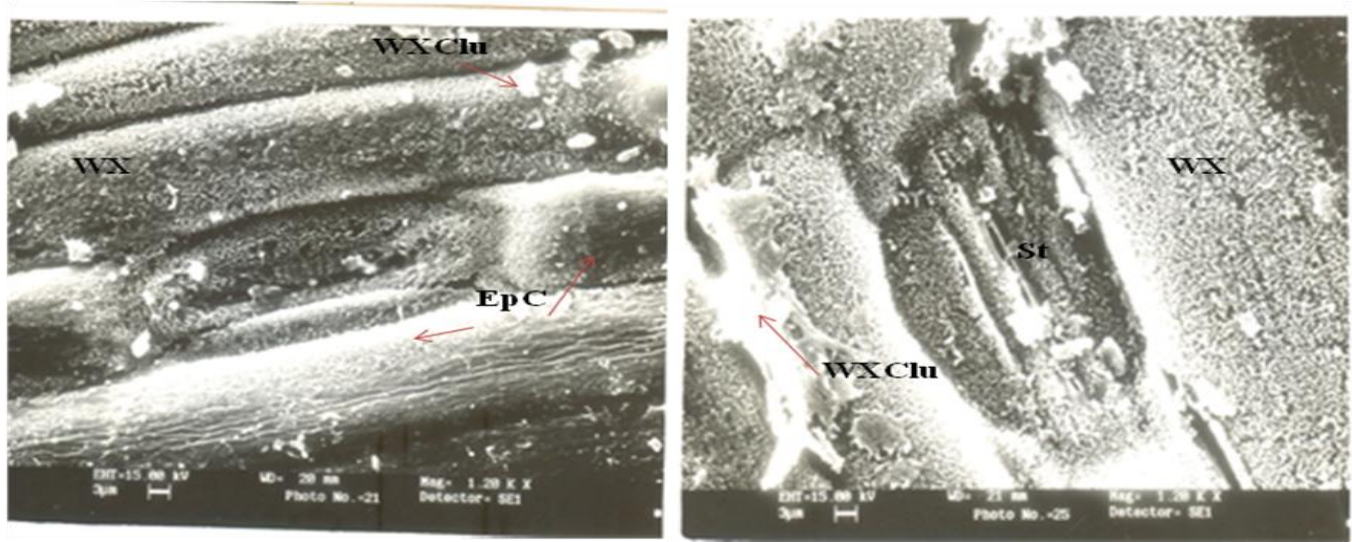

Plate.1 Morphology of wax crystal (WXC-tubular network type) of cuticle on epidermal cells (EpC) and stomata (St) of drought sensitive (HD2428) and drought tolerant (C306) cultivar of wheat under unfavorable growth conditions (January sown) *WXClu- Wax cluster

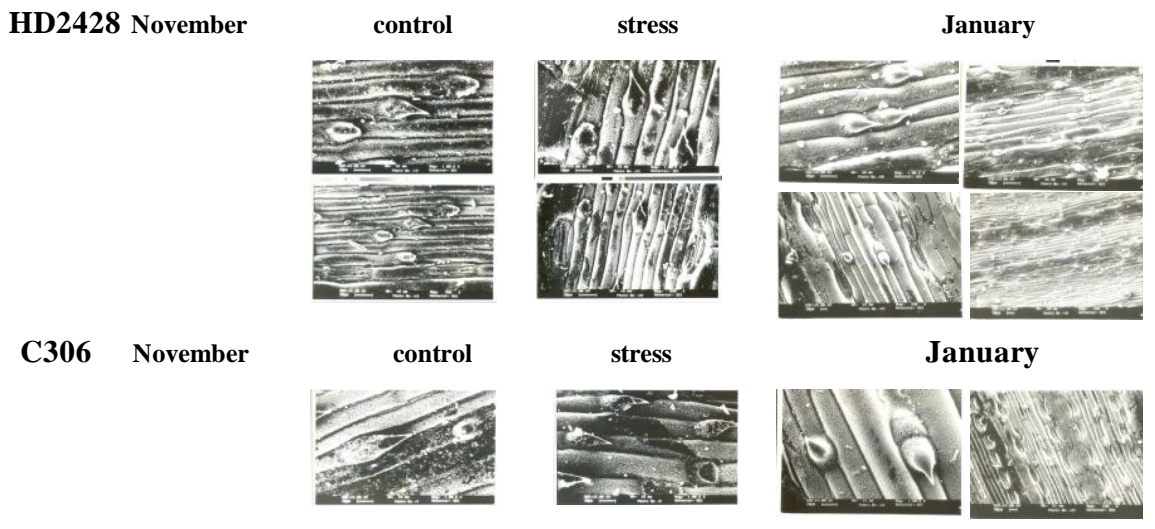

Plate.2 Trichomes and wax formation on epidermis of flag leaves of contrasting wheats; Drought sensitive wheat cultivar HD2428 and Drought tolerant wheat cultivar C306 under normal

(November) and unfavorable growth conditions (January sown)

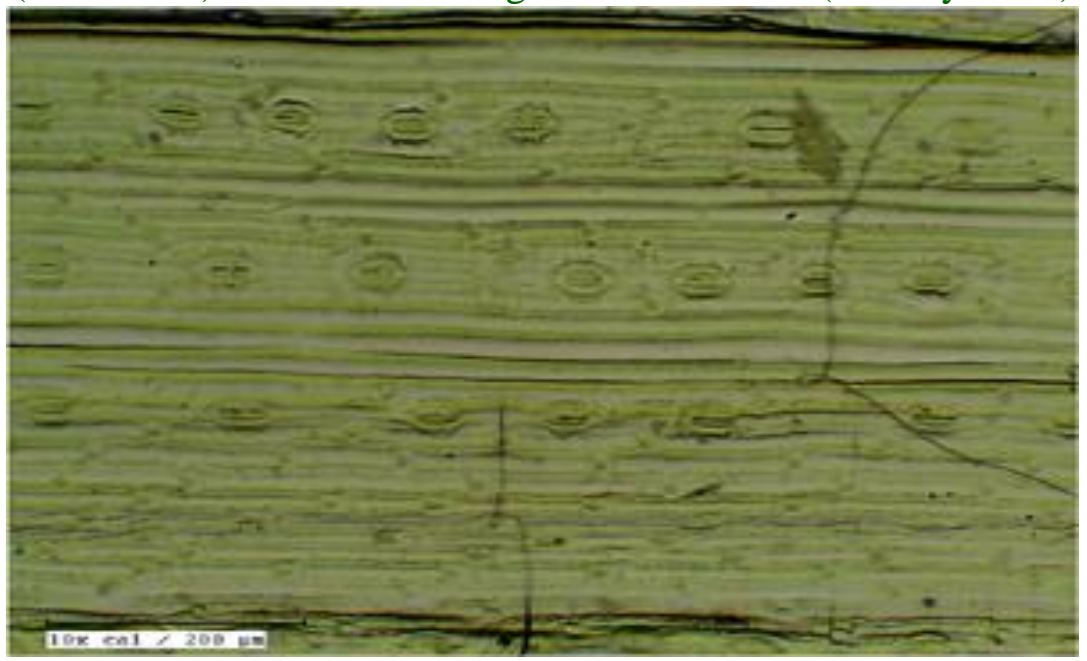

Plate.3A Stomatal and Trichomes distribution on flag leaves of drought sensitive cultivar of wheat - HD2428 under normal conditions of growth 


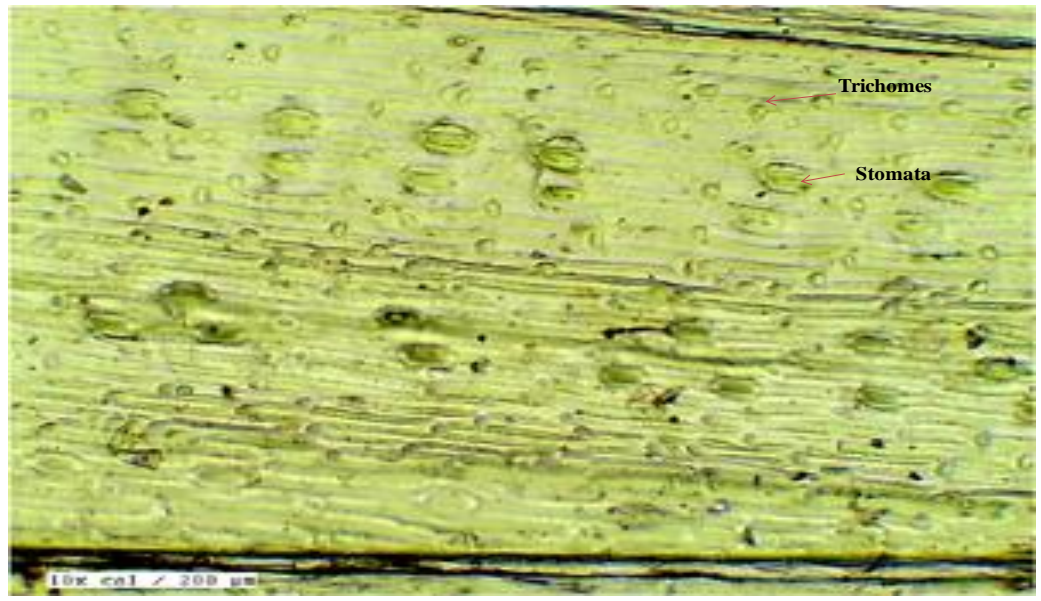

Plate.3B Hydrogen Peroxide sprayed flag leaves of drought sensitives cultivar of wheat HD2428; Number of stomata and trichomes increased under normal conditions of growth

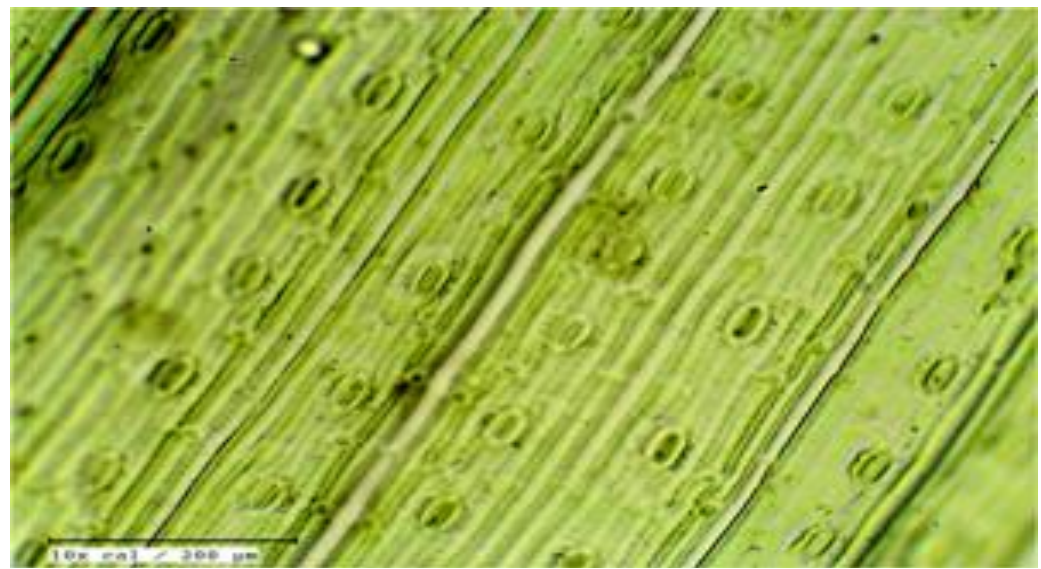

Plate.3C Stomatal and Trichomes distribution on flag leaves of drought tolerant cultivar of wheat - C306 under normal conditions of growth

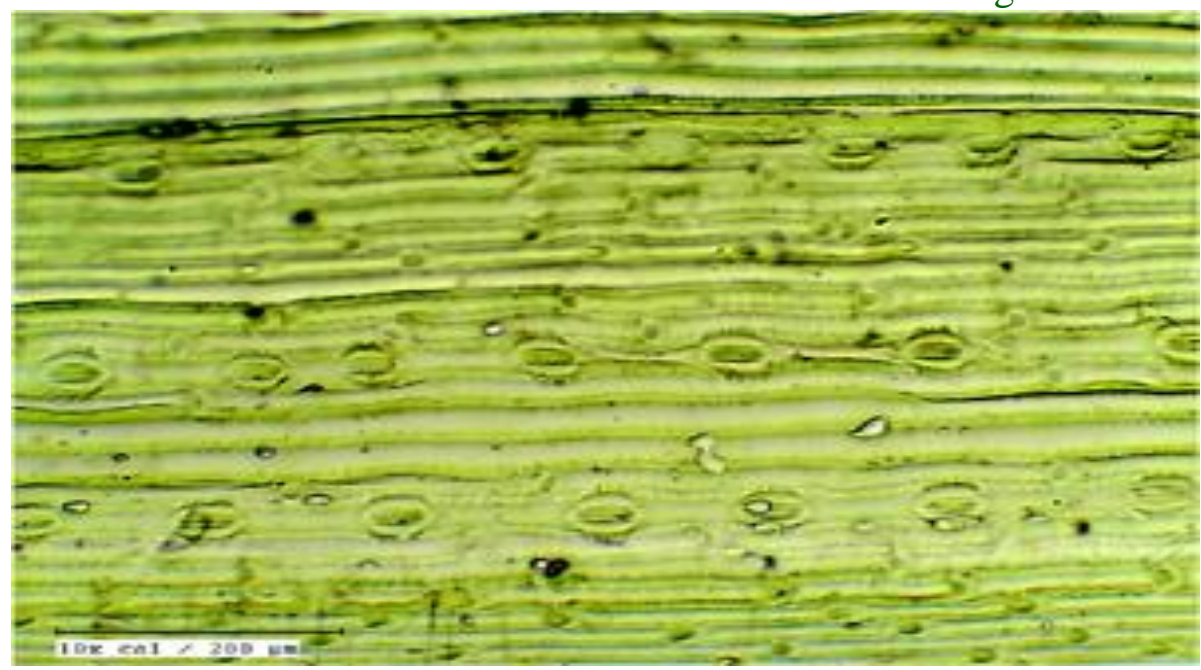

Plate.3D Hydrogen Peroxide sprayed flag leaves of drought tolerant cultivar of wheat - C306;

Number of trichomes increased under normal conditions of growth 


\section{Acknowledgement}

Scanning electron microscopy (SEM) under microscope LEO 435 VP (Fei Electron optics) facility provided by AIIMS, Delhi is thankfully acknowledged.

\section{References}

Corsi, G. and Bottega, S. (1999) Glandular hairs of Salvia officinalis: New data on morphology, localization and histochemistry in relation to function. Ann. Bot. 84: 657-664.

Gershenzon, J., Duffy, M. A., Karp, F. and Croteau, R. (1987) Mechanized techniques for the selective extraction of enzymes from plant epidermal glands. Anal. Biochem. 163: 159-164.

Kandra, I., Severson, R. and Wagner, G. J. (1990) Modified branched chain amino acid pathways give rise to acyl acids of sucrose esters exuded from tobacco leaf trichomes. Eur. J. Biochem. 188: 385391.

Kiran, S.R. and Devi, P.S. (2007) Evaluation of mosquitocidal activity of essential oil and sesquiterpenes from leaves of Chloroxylon swietenia DC. Parasitology Res. 101: 413-418.

Moradkhani, H., Sargsyan, E., Bibak, H., Naseri, B., Sadat-Hosseini, M., FayaziBarjin, A. and Meftahizade, H. (2010) Melissa officinalis L., a valuable medicine plant: a review. J. Med. Plants Res. 4: 2753-2759.

Pinho-da-Silva, L., Mendes-Maia, P. V., Teófilo, T. M., Barbosa, R., Ceccatto, V. M., Coelho-deSouza, A. N., Cruz, J. S. and Leal-Cardoso, J. H. (2012) Trans-caryophyllene, a natural sesquiterpene, causes tracheal smooth muscle relaxation through blockade of voltage-dependent $\mathrm{Ca} 2+$ channels. Molecules 17: 11965-11977.

Rodrigues, L., Póvoa, O., Teixeira, G., Figueiredo, A. C., Moldão, M. and Monteiro, A. (2013) Trichomes micro morphology and essential oil variation at different developmental stages of cultivated and wild growing Mentha pulegium L. populations from Portugal. Indus. Crops Prod. 43: 692-700.

\section{How to cite this article:}

Santosh Kumari and Vipin Kumar Verma. 2020. Trichomes and Cuticular Wax Morphology on Flag Leaves of Drought Sensitive and Drought Tolerant Wheat (Triticum aestivum L.) under Unfavourable Growth Conditions. Int.J.Curr.Microbiol.App.Sci. 9(02): 2740-2747. doi: https://doi.org/10.20546/ijcmas.2020.902.311 